\title{
28 Research Square \\ The epidemiological trends of coronavirus disease (COVID-19) in Iran: February 19 to March 22, 2020
}

\section{Dr. Farzan Madadizadeh}

Research Center of Prevention and Epidemiology of Non-Communicable Disease, Department of Biostatistics and Epidemiology, School of Public Health, Shahid Sadoughi University of Medical Sciences Reyhane Sefidkar ( $\square$ reyhanesefidkar@gmail.com )

Department of Biostatistics, Shahid Beheshti University of Medical Sciences, Tehran, Iran.

\section{Research Article}

Keywords: Respiratory illness, Coronavirus disease 2019, Primary health care, Epidemiology

Posted Date: May 18th, 2020

DOl: https://doi.org/10.21203/rs.3.rs-29367/v1

License: (우 This work is licensed under a Creative Commons Attribution 4.0 International License. Read Full License 


\section{Abstract}

Background The Coronavirus has crossed the geographical borders of various countries without any restrictions. This study was performed to identify the epidemiological trends of coronavirus disease (COVID-19) in Iran during February 19 to March 22, 2020.

Methods This cross sectional study was carried out in 31 provinces by using the daily number of newly infected cases which was announced by the Iranian health authorities from February 19 to March 22, 2020, we explore the trend of outbreak of coronavirus disease in all provinces of Iran and determine some influential factors such as population size, area, population density, distance from original epicenter, altitude, and human development index ( $\mathrm{HDI}$ ) for each province on its spread by Spearman correlation coefficient. K-means cluster analysis (KMCA) also categorized the provinces into 10 separate groups based on $\mathrm{CF}$ and $\mathrm{ACF}$ of the infected cases at the end of the study period. (ACF).

Results There were 21,638 infected, 7,913 recovered and 2,299 death cases with COVID-19 in Iran during the study period. By March 22, CF shows that, most cases are attributed to Tehran province, while ACF shows that most are attributed to Semnan province. There was a positive significant correlation between CF of the infected cases and province population sizes ( $r=0.45), \mathrm{HDI}(\mathrm{r}=0.58)$; province population density $(r=0.47)$; a negative significant correlation between the $\mathrm{CF}$ of the infected cases and distance from original epicenter ( $r=-0.47)$. KMCA results based on CF showed very high level of outbreak was in Tehran while KMCA based on ACF showed very high level of outbreak were in Semnan and Qom provinces.

Conclusions Special attention is needed for the provinces nearer to the original epicenter which are high risk spots in terms of the severe prevalence of COVID-19. In the absence of definite treatment for this infectious disease, the effective solutions to reduce the transmission of the disease are early isolation of the cases, quarantine for close contacts both in families and community and observing personal hygiene.

\section{Background}

These days, a strange unwanted guest has drastically surprised the people in most of the countries all over the world. That is a 2019 novel coronavirus (2019-nCoV), which is a new member of coronavirus family mainly causes acute infection in the human respiratory system at early stages [1]. This new coronavirus first emerged in December 2019 in China by identifying a cluster of pneumonia cases of unknown etiology and was identified from the throat swab sample of a patient on January 7 [2-3]. The International Committee on Taxonomy of Viruses (ICTV) called the newly described coronavirus as Severe Acute Respiratory Syndrome Coronavirus 2 (SARS-CoV-2) and the caused disease as coronavirus disease-2019 (COVID-19) [4]. Up to now, the world has witnessed the deadly and destructive outbreak of various coronavirus-related diseases including SARS during 2002-2003 and Middle East respiratory syndrome (MERS) in 2012 with a case fatality rate of 10 and $35.5 \%$, respectively [5-6]. Researches have shown that the COVID-19 has a humantohuman transmission and its incubation period varies between 2-14 days [7-8]. Although, the transmission mostly occurs when a patient is symptomatic, the studies have indicated that it may also happen during the asymptomatic incubation period [9]. Clinical manifestations of this disease 
include fever, cough, shortness of breath, and breathing difficulties and other complications related to respiratory tract involvement so that, in more severe cases infection can cause pneumonia, severe acute respiratory syndrome, and even death [7-9]. Based on the warnings, older adults and people with serious heart disease, diabetes and lung disease may hurt severely from the COVID-19 [10]. Long infectious period, rapid increases in the number of cases and the absence of definitive treatment have made this disease a global challenge [11-12]. Until March 22, 2020, the total number of infected cases worldwide is 337,459, 14,640 of which have lost their lives. While china has the most total confirmed cases, the peak of mortality due to the COVID-19 has been reported in Italy with a total number of 5,476 deaths [13]. On 19 February 2020, the first death cases due to the COVID-19 were announced in Qom province (Iran), after that, the ascending trend of outbreak was started across the other provinces. According to the Ministry of Health and Medical Education (MHME) reports, up to March 22, 2020, there were 21,638 confirmed cases in Iran with 1,685 deaths and 7,913 remissions, and Tehran province has been reported to have the highest number of infected cases among the other provinces. Although the authorities have started to confront this epidemic by shutting down the schools and universities, refusing non-local travelers in some provinces, reducing working hours for some days, implementing forms of remote work by many companies for the employees, requesting the individuals to stay at home in self-quarantine, etc., still there is a quick increase in the number of infected cases [5]. According to the literature review, there are limited published papers on Iran's status in the outbreak period of the COVID-19 [5, 14-18]. Therefore, given the rapid outbreak of the COVID-19 in Iran, this study was conducted in order to identify the spreading trend of this disease in Iran and all its provinces from February 19 to March 22, 2020, using the recorded data from the MHME and also to find similar provinces according to the disease spread using K-means cluster analysis (KMCA).

\section{Methods}

Data collection

During the study period, from February 19 to March 22, 2020, the daily provincial distribution of the epidemic was closely tracked, extracted and collected through various sources including MHME and www.worldometers.info/coronavirus.

The information included the daily number of newly confirmed cases, remissions and deaths due to the COVID-19 in all the 31 provinces of Iran within a 33-day interval. Based on the last population census conducted in 2016 in Iran, the population of Iran is about 79.9 million people. Table 1 presents the information on the cumulative frequency of the infected cases, population size, area, population density, distance from original epicenter (Qom province), altitude from sea level, and Human Development Index (HDI) for each province. According to Table 1, Tehran, Khorasan Razavi, and Isfahan are the most populous provinces, respectively. Kerman, Sistan and Baluchestan, and South Khorasan are the largest provinces, respectively. Tehran, Alborz, and Gilan have the highest population density, respectively. Tehran, Alborz, and Esfahan are the provinces with the highest HDI and Sistan and Baluchestan, Kurdistan, and North Khorasan are the provinces with the lowest HDI, respectively.

Statistical analysis 
Results regarding the descriptive statistics showed the trend related to the number of newly confirmed, recovered, and death cases for the COVID-19 during the study period through the plots provided in the Excel software. Also, the RStudio version 1.2.5042 software was used to map cumulative frequency (CF) and adjusting the cumulative frequency of the confirmed cases (ACF) with respect to population of each province (based on Iran's 2016 population census) in order to visualize the distribution of the epidemic. Furthermore, the spearman correlation coefficient was calculated to assess the strength of the linear relationship between CF and the variables presented in Table 1. KMCA was also applied to identify the provinces with similar spreading pattern in terms of the COVID-19 outbreak. Cluster analysis is a method used to classify a sample of objects with different features into different groups so that, the objects in the same category (called a cluster) are more similar than those in other categories. In this study, K-means clustering technique was employed. It is a distance-based algorithm, where the distances are calculated to assign a point to a cluster. In this method, each cluster is associated with a centroid and the aim is minimizing the sum of distances between the points and their respective cluster centroid [19]. The number of iterations was set as 100 and the number of clusters was set as 10.

\section{Results}

Figure 1. shows the number of newly infected, death ,and recovered cases due to the COVID -19 from February 19 to March 22, 2020 in Iran. During the study period, maximum number of newly infected, death, and recovered cases were on March 14 with 1365 cases, March 19 and 20 with 149 cases, and March 20 with 890 cases, respectively. Qom province, as the seventh most populous city of Iran, with the geographical coordinates of $34.66 \mathrm{~N}$, and $50.88 \mathrm{E}$ was the first province of Iran contaminated with the Coronavirus on February 19, 2020 with 2 cases and Bushehr province was the last province with five cases on March 5, 2020. On March 22, 2020, 1028 new cases were reported in Iran that large number of them were from Tehran with 249 cases (24.22\%), Isfahan with 87 cases (8.46\%), Yazd with 84 cases (8.17\%), Alborz with 60 cases (5.83\%), and East Azerbaijan with 57 cases (5.54\%) and also Bushehr, Kohgiluyeh and Boyer-Ahmad and Semnan provinces did not have any new case. In Tehran and Isfahan provinces, the maximum number of new cases was reported on March 3, and March 11, 2020 just in 11 and 16 days after its starting day. In other provinces such as Yazd, Markazi and East Azarbaijan, maximum number of new cases was reported in March 22, with 84 newly confirmed cases, March 14 with 134 newly confirmed cases, and March 13, 2020, with 97 newly confirmed cases, respectively (see Figure 2.). Cumulative frequency of the confirmed cases from February 19 to March 22 in Iran was equal to 21638. It is mapped separately for all the provinces in Figure 3. Among the provinces of Iran, maximum CF was observed in Tehran with 5098 cases (23.56\%), Isfahan with 1976 cases (9.13\%), Mazandaran with 1700 cases (7.85\%), Gilan with 1191 cases (5.5\%), Qom with 1178 cases (5.44\%), and Alborz with 1177 cases (5.44\%). Also, minimum CF was observed in Bushehr with 55 cases (0.25\%), Chaharmahal and Bakhtiari with 68 cases (0.31\%), and Kohgiluyeh and Boyer-Ahmad with $73(0.34 \%)$ cases. ACF of the confirmed cases in the population of each province provides more accurate picture of the epidemic which is mapped in Figure 4. According to ACF, based on 1000000 million population, cumulative frequency of the infected cases was equal to 270.72 in Iran among which the maximum adjusting cumulative frequencies belonged to the provinces of Semnan

(918.33), Qom (911.56), Yazd (636.78), Markazi (617) ,and Qazvin (525.22), and minimum values were 
observed in Bushehr (33.71), Sistan and Baluchestan (48.29) ,and Kerman (57.5). Figure. 5 shows the CF, new cases, recovered and death per day in Iran. As demonstrated in Figure. 5, there is an increasing trend in CF in Iran. Results of the KMCA based on CF and also ACF of the confirmed cases showed that all the 31 provinces of Iran are classified into 10 clusters according to the similarity index of Euclidean distance (Table 2). In clustering based on the CF, Tehran and Isfahan had a separate specific cluster but in clustering based on ACF, they had common cluster. Fars and Khuzestan, Chaharmahal and Bakhtiari and Bushehr, Gilan and Alborz had same cluster in both types of clustering. There was a positive significant relationship between the CF and province population $(r=0.45, p=0.01), C F$ and population density $(r=0.47, p=0.002), C F$ and $\mathrm{HDI}(r=0.58, p=0.001)$, and also there was a negative significant relationship between $\mathrm{CF}$ and distance from Qom province $(r=-0.47, p=0.002)$. There was a negative insignificant relationship between $C F$ and area $\left(\mathrm{km}^{2}\right)(r=-0.12, p=0.51)$, and height above sea level $(r=-0.130, p=0.494)$.

\section{Discussion}

The Coronavirus has crossed the geographical borders of various countries without any restrictions and has caused almost 199 countries in the world to confront the challenges of the disease, death of their citizens, economic pressure, and other issues [20]. Totally, 337459 confirmed cases were recorded from February 19 to March 22, 2020 in the world [21]. Iran was ranked sixth after countries of China, Italy, Spain, United States, Germany with $6.4 \%$ (21638 people) of the confirmed cases, $11.5 \%$ (1685 people) of deaths, and 8\% (7840 people)of the recovered cases (Fig. 6) [21]. As shown in Fig. 5, from February 19 to March 6 (16 days), two days after the first incubation period of the disease (14 days), the highest number of new cases was recorded on March 6 with 1234 confirmed cases, and nine days later, 1365 new cases were recorded again on March 14. Despite the declining trend in the number of new cases, a huge number of 1237 new cases were recorded again on March 20. Considering the increasing trend on March 22, it seems that the number of new cases and CF will increase in the coming days [22]. Investigating the Iran's provinces with respect to the Coronavirus epidemic showed that Qom province with two confirmed cases was the first province in disease spreading on February 19, and after that, its adjacent provinces such as Tehran, Markazi, and Isfahan were infected. Results of our study showed a negative significant relationship between the CF of the confirmed cases in different provinces with distance from Qom so that, epidemic was more in the provinces with smaller distance from Qom. In other words, $22 \%\left(0.47^{2}\right)$ of variation in the number of confirmed cases was related to the distance from epidemic center.

Tehran province with 13 million population (17.5\% of Iran population) was the first in ranking based on both number of the confirmed cases per day and cumulative number of confirmed cases while, it was not in the category of provinces with high infection after adjusting the cumulative number of the confirmed cases with respect to population of each province. It seems that ACF gives a more realistic description of disease status in each province. According to this adjustment, contrary to the image created by the daily frequency and CF where Tehran, Isfahan, and Markazi provinces were not in a good position, the results of ACF showed that Semnan, Qom, Yazd, Markazi, and Qazvin provinces were in critical condition and needed special attention. As depicted in Fig. 1., it seems that some provinces have passed the incubation period, 
but others have to wait. For example, in Tehran province, the number of new cases reached its peak on March 3, after which, a declining and then increasing trend were reported in the number of the patients.

Although, the daily cumulative trend in the number of patients had an upward trend in most provinces, in general, the process of registering new daily cases of the Coronavirus from February 19 to March 22, 2020, in the provinces of Iran can be divided into three categories of downward, upward, and irregular so that Tehran, Qom, Mazandaran, Golestan, Khorasan Razavi, Khuzestan, and Chaharmahal and Bakhtiari provinces showed a downward trend, Fars, Yazd, Zanjan, Hamedan, Sistan -Baluchistan, and West Azarbaijan showed an upward trend, and other provinces showed an irregular trend.

KMCA was used in the present study to identify the existing similarities in the process of virus infection in the provinces. All the provinces were clustered once based on the CF and again based on ACF. The results of KMCA based on CF of the confirmed cases pointed out that among six provinces with the highest frequency of infected cases, Tehran, Isfahan, and Mazandaran provinces had an independent trend so that, they had specific cluster, but Qom, Gilan, and Alborz had similar trend and common cluster. The results of KMCA based on the ACF of the confirmed cases also showed a similar dual trend in the six provinces with the highest frequency. In other words, some provinces such as Qom and Semnan, Markazi and Yazd, Mazandaran and Qazvin had a similar pattern of infection. Clustering provinces with the aforementioned pattern can contribute enormously to implementing similar emergency measures and developing joint control programs for the above-mentioned provinces.

Our results also showed that population, population density, $\mathrm{HDI}$ were the three influential factors on the CF of the confirmed cases so that, $20 \%\left(0.45^{2}\right), 22 \%\left(0.47^{2}\right)$, and $33 \%\left(0.58^{2}\right)$ of CF variation was related to each of them, respectively. Due to high contamination of the virus, the more populated the province and the denser the population, the easier and faster it is to spread the virus. But the relationship between the HDI, as an indicator of education, life expectancy, and per capita income, and spread of the virus was unexpected.

During the disease epidemic in Iran, the government first considered emergency measures for the center of the disease epidemic, the Qom province, and after that by observing new cases in Tehran, Gilan, and Mazandaran provinces, which are the adjacent provinces to Qom province, the emergency measures for these three provinces were considered as well [23]. Sending medical teams, suspending transportation and banning the entry and exit (lock down), and closing the schools and universities were some of the emergency measures needed at this level. Gradually, the scope of the virus epidemic was expanded and the virus spread to neighboring provinces. Finally, on March 5, 2020, all the 31 provinces of Iran became involved in the epidemic. Following this epidemic, the Iranian government established some specialized epidemiology committees for reporting and combating the Coronavirus at the national and provincial levels. The Provincial Committees on Combating the Coronavirus were formed under the auspices of the Ministry of Health's forces and on the advice of the professors from universities of medical sciences and trained personnel of the healthcare centers. The president provided the Ministry of Health with the necessary powers to fight the disease, and the national military forces cooperated fully with the Ministry of Health. Later, all the gatherings of people including religious sites were banned. A new Scientific and Technical Committee was established to guide the epidemiological studies, determine the type of 
interventions, prepare the necessary guidelines in accordance with the recommendations of World Health Organization (WHO) for people from all different walks of life [24], with various occupations, and also inform the public by mass media and social networks. The valuable experiences of other countries including China were also used. Subsequently, an online screening system was launched and the community was asked to record the required information) www.salamat.gov.ir). The case detection program was also activated through 5,000 healthcare centers and 17,000 health homes in urban and rural areas. Mobile health centers were set up to initially identify the infected people across the provinces in order to reduce the number of patients referring to the main hospitals dedicated to the Coronavirus disease. Equipping and preparing more hospitals, disinfecting the urban public places, closing all the centers except those providing the peoples' basic necessities, recruiting new staff in the medical staff of the Ministry of Health and calling on the retired workers to return to work, encouraging the local manufacturers to produce the masks, goggles, disinfectant liquids and gels, and medical staff uniforms, agreeing with Iran's neighbors to further control the borders, calling for cooperation with international organizations to provide laboratory kits and medical equipment, encouraging the people to be quarantined at home, establishing an extended-care facility for the 14-day rest of the recovered patients after discharge and before going home and being around the family members, and formation of a psychology task force to reduce the stress of the patients and ordinary people were among the other measures taken by the government in this regard. Despite strong international sanctions against Iran, all the activities were encouraged and approved by the WHO's expeditionary team during a visit to monitor the Iran's control activities in the fight against the Coronavirus. At the time of writing this Paper, the Iranian New Year (Nowruz) began and since this time is an opportunity for the families and friends to visit each other according to the Iranian tradition, the government banned all the trips and visits and asked the people for using digital facilities instead of direct exposure to each other [25]. Also, in addition to activating the highest level of measures to combat the Coronavirus, a plan called Social Distancing was implemented for minimizing the contacts between ordinary people, the entry and exit of non-indigenous people were prevented in all the Iranian cities and villages, and heavy fines were imposed on the passengers. The government also extended the New Year holidays and all the government departments were asked to continue working with only $30 \%$ of their employees in addition to observing the healthcare instructions. The Iranian army and military forces have pledged to build a 2,000-bed hospital for the patients infected by the Coronavirus on March 25. The government also suspended loan repayments and tax payments and promised to give cheap supportive loans to support the economy. Various epidemiological studies have been conducted on the Coronavirus using several different samples obtained from 41,99 and 138 patients and the characteristics of individuals such as age, sex, family history of heart disease, blood pressure, and diabetes were investigated $[26,2,27]$. The present study was carried out to investigate the incidence of COVID-19 in different provinces of Iran and there was no possibility to have access to the individuals' characteristics.

The reports on modeling and prediction of the Coronavirus status in the country conducted by the Iranian Ministry of Health have stated that if isolation levels were $25 \%$ on March 10 , the number of cumulative deaths would be 13450 in the whole country by May 20; if isolation levels raised to $32 \%$, the number of deaths would be 8630 ; and if isolation levels reached by $40 \%$, the number of deaths would be 6030 [28]. Extensive research studies are underway worldwide to discover the treatment for the Coronavirus disease. 
Some studies have considered the isolation as one of the most effective ways to preserve the patients' lives and found that the discovery of a specific drug takes several years Similar to what John Snow did for cholera in the 18th century in London, further research is needed to be done to discover the origin and complete treatment of the disease [29]. Focusing on finding the right response to the crisis should not lead to neglect providing routine care to the people in the community so that, finally, the number of patients who have died due to lack of access to health care will exceed the number of deaths due to the Coronavirus. The incidence of the COVID-19, as the biggest crisis since World War II, gives rise to promote the environmental health, reduce the air pollution, decrease the road accident fatalities, and increase the national solidarity among different walks of life despite the problems created for the healthcare system and global economic system.

\section{Conclusions}

In a nutshell, the COVID-19 as an infectious and destructive disease has a considerable Transmission speed in Iran. It seems that the outbreak of this infectious disease is more in provinces nearer to the original epicenter and also more populated province. For now, since there is not any vaccines or treatment, the primary tool is to control the prevalence by detecting and isolating the cases. Although the authorities adopt some appropriate policies in this regard, but, to stop the epidemic, it is needed to purse more strict policies in order to decline the number of new cases to less than one.

\section{Abbreviations}

SARS-CoV-2: Severe Acute Respiratory Syndrome Coronavirus 2; CF: Cumulative Frequencies; ACF: Adjusted Cumulative Frequencies; COVID-19: Coronavirus disease-2019; 2019-nCoV: 2019 novel coronavirus; ICTV: International Committee on Taxonomy of Viruses; MERS: Middle East respiratory syndrome; MHME: Ministry of Health and Medical Education; KMCA: K-means cluster analysis; HDI: Human Development Index; WHO: World Health Organization

\section{Declarations}

\section{Ethics approval and consent to participate}

Ethics License of the present study was acquired from the Ethics Committee of Shahid Sadoughi University of Medical Sciences (Code of ethics: IR.SSU.REC.1399.033).

\section{Consent for publication}

Not applicable.

\section{Availability of data and materials}

The datasets used and/or analysed during the current study are available from the corresponding author on reasonable request. 


\section{Competing interests}

The authors declare that they have no competing interests.

\section{Funding}

No external funding was used in the preparation of this paper.

\section{Authors' contributions}

FM had the conception for and designed the study, and take responsibility for the integrity of the data and the accuracy of the data analysis. FM and RS contributed to the data acquisition and the statistical analysis and interpretation. All authors contributed to data acquisition, data analysis, or data interpretation, and reviewed and approved the final version.

\section{Acknowledgements}

Not applicable.

\section{References}

1. Rothan HA, Byrareddy SN. The epidemiology and pathogenesis of coronavirus disease ( COVID-19) outbreak. J Autoimmun. 2020 Feb 26:102433. Available from: https://doi.org/10.1016/j.jaut.2020.102433.

2. Chen N, Zhou M, Dong X, Qu J, Gong F, Han Y, et al. Epidemiological and clinical characteristics of 99 cases of 2019 novel coronavirus pneumonia in Wuhan , China: a descriptive study. The Lancet. 395(10223):507-13. Available from: http://dx.doi.org/10.1016/S0140-6736(20)30211-7.

3. Hsu LY, Chia PY, Lim JFY. The Novel Coronavirus ( SARS-CoV-2 ) Epidemic. Ann Acad Med Singapore. 2020;49:1-3.

4. Shereen MA, Khan S, Kazmi A, Bashir N, Siddique R. COVID-19 infection: origin, transmission, and characteristics of human coronaviruses. J Adv Res. 2020; Available from: https://doi.org/10.1016/j.jare.2020.03.005.

5. Dehkordi AH, Alizadeh M, Science C, Derakhshan P, Babazadeh P, Jahandideh A. Understanding epidemic data and statistics: A case study of COVID-19. arXiv Prepr arXiv200306933. 2020.

6. Chang L, Yan Y, Wang L. Coronavirus Disease 2019: Coronaviruses and Blood Safety. Transfus Med Rev. 2020; Available from: https://doi.org/10.1016/j.tmrv.2020.02.003.

7. Rahimzadeh G, Noghabi ME, Elyaderani FK, Navaeifar MR, Enayati AA, Manafi A, et al. Case Report: COVID-19 Infection in Iranian Children: A Case Series of 9 Patients. J Pediatr Rev. 2020;8(2):139-44.

8. Province $\mathrm{H}$. The Novel Coronavirus Originating in Wuhan , China Challenges for Global Health Governance. Jama. 2020;323(8):709-10.

9. Sohrabi C, Alsafi Z, Neill NO, Khan M, Kerwan A, Al-jabir A, et al. World Health Organization declares global emergency: A review of the 2019 novel coronavirus ( COVID-19). Int J Surg. 2020; Available 
from: https://doi.org/10.1016/j.ijsu.2020.02.034.

10. CDC. People Who Are at Higher Risk for Severe Illness. Available from: https://www.cdc.gov/coronavirus/2019-ncov/specific-groups/high-risk-complications.html

11. Cunningham AC, Goh HP, Koh D. Treatment of COVID-19: old tricks for new challenges. 2020.

12. Wilson M, Chen L. Travellers give wings to novel coronavirus (2019-nCoV). 2020.

13. WORLDMAPPER. Covid-19 (Coronavirus) Update: Chronology of a Pandemic. Available from: https://worldmapper.org/covid-19-coronavirus/.

14. Arab-Mazar Z, Sah R, Medicity MT, Rabaan A, Dhama K, Rodriguez-morales AJ. Mapping the incidence of the COVID-19 hotspot in Iran - Implications for Travellers Letter to the Editor Mapping the incidence of the COVID-19 hotspot in Iran - Implications for Travellers. Travel Med Infect Dis. 2020.

15. Tuite A, Bogoch I, Sherbo R, Watts A, Fisman D, Khan K. Estimation of COVID-2019 burden and potential for international dissemination of infection from Iran. medRxiv 2020.

16. Muniz-Rodriguez K, Fung I, Ferdosi S, Ofori S, Lee Y, Tariq A, et al. Transmission potential of COVID-19 in Iran. medRxiv. 2020.

17. Zhan C, Tse CK, Lai Z, Hao T, Su J. Prediction of COVID-19 Spreading Profiles in South Korea, Italy and Iran by Data-Driven Coding. medRxiv. 2020.

18. Zhuang Z, Zhao S, Lin Q, Cao P, Lou Y, Yang L, et al. Preliminary estimation of the novel coronavirus disease (COVID-19) cases in Iran: A modelling analysis based on overseas cases and air travel data. Int J Infect Dis. 2020;94:29-31. Available from: https://doi.org/10.1016/j.jijd.2020.03.019.

19. Dunn H, Quinn L, Corbridge S, Eldeirawi K, Kapella M, Collins E. Cluster Analysis in Nursing Research: An Introduction, Historical Perspective, and Future Directions. West J Nurs Res. 2018;40(11):1658-76.

20. Saghazadeh A, Rezaei N. Immune-epidemiological parameters of the novel coronavirus-a perspective. Expert Rev Clin Immunol. 2020; Available from: https://doi.org/10.1080/1744666X.2020.1750954.

21. Worldmeters. COVID-19 CORONAVIRUS PANDEMIC. Available from: https://www.worldometers.info/coronavirus.

22. Wright R. THE NEW YORKER. How Iran Became a New Epicenter of the Coronavirus Outbreak. 2020.

23. Wikipedia. 2020 coronavirus pandemic in Iran. Available from: https://en.wikipedia.org/wiki/2020_coronavirus_pandemic_in_Iran.

24. World Health Organization. Rational use of personal protective equipment for coronavirus disease (COVID-19): interim guidance. 27 Febr 2020. :World Health Organization; 2020.

25. UN. What is Nowruz and why do we celebrate it? Available from: https://www.un.org/en/observances/international-nowruz-day.

26. Huang C, Wang Y, Li X, Ren L, Zhao J, Hu Y, et al. Clinical features of patients infected with 2019 novel coronavirus in Wuhan, China. The Lancet. 395(10223):497-506.

27. Wang D, Hu B, Hu C, Zhu F, Liu X, Zhang J, et al. Clinical characteristics of 138 hospitalized patients with 2019 novel coronavirus-infected pneumonia in Wuhan, China. Jama. 323(11):1061-9.

28. MHME. Available from: http://corona.behdasht.gov.ir/. 


\section{Tables}

Table 1. Demographic features, cumulative frequency and adjusted cumulative frequency of the cases in provinces of Iran.

\begin{tabular}{|c|c|c|c|c|c|c|c|c|c|c|}
\hline No. & Province & $\mathrm{CF}^{*}$ & $\begin{array}{l}\text { CF/ Sum } \\
\text { of CFs }\end{array}$ & $\begin{array}{l}\text { Population } \\
\text { Census } \\
2016\end{array}$ & $\mathrm{ACF}^{* *}$ & Area $\left(\mathrm{km}^{2}\right)$ & $\begin{array}{l}\text { Altitude(height } \\
\text { above sea) }\end{array}$ & $\begin{array}{l}\text { Population } \\
\text { density } \\
\left(\text { people } / \mathrm{km}^{2} \text { ) }\right.\end{array}$ & $\begin{array}{l}\text { Distance from } \\
\text { original } \\
\text { Epicenter(Qom) }\end{array}$ & HDI*** \\
\hline 1 & Tehran & 5098 & 0.235604 & 13267637 & 384.4645551 & 18814 & 1368 & 704.8 & 145 & 0.834 \\
\hline 2 & Qom & 1178 & 0.054441 & 1292283 & 911.5650365 & 11240 & 932 & 115.0 & 0 & 0.816 \\
\hline 3 & Gilan & 1191 & 0.055042 & 2530696 & 470.6215207 & 14042 & -8 & 180.2 & 672 & 0.805 \\
\hline 4 & Isfahan & 1976 & 0.091321 & 5120850 & 385.873439 & 107018 & 1571 & 47.9 & 283 & 0.83 \\
\hline 5 & Alborz & 1177 & 0.054395 & 2712400 & 433.9330482 & 5833 & 1380 & 465.0 & 165 & 0.834 \\
\hline 6 & Mazandaran & 1700 & 0.078565 & 3283582 & 517.7337515 & 23756 & 54 & 138.2 & 390 & 0.825 \\
\hline 7 & Markazi & 882 & 0.040762 & 1429475 & 617.0097413 & 29127 & 1708 & 49.1 & 131 & 0.791 \\
\hline 8 & Qazvin & 669 & 0.030918 & 1273761 & 525.216269 & 15567 & 1297 & 81.8 & 234 & 0.796 \\
\hline 9 & Semnan & 645 & 0.029809 & 702360 & 918.3324791 & 97491 & 1130 & 7.2 & 281 & 0.822 \\
\hline 10 & Golestan & 391 & 0.01807 & 1868819 & 209.2454374 & 20117 & 1065 & 92.9 & 524 & 0.778 \\
\hline 11 & $\begin{array}{l}\text { Razavi } \\
\text { Khorasan }\end{array}$ & 858 & 0.039652 & 6434501 & 133.3436734 & 118018 & 1065 & 54.5 & 956 & 0.781 \\
\hline 12 & Fars & 505 & 0.023339 & 4851274 & 104.0963673 & 122608 & 1549 & 39.6 & 760 & 0.808 \\
\hline 13 & Lorestan & 476 & 0.021998 & 1760649 & 270.3548521 & 28294 & 1347 & 62.2 & 334 & 0.779 \\
\hline 14 & $\begin{array}{l}\text { East } \\
\text { Azerbaijan }\end{array}$ & 813 & 0.037573 & 3909652 & 207.9468966 & 45651 & 1345 & 85.6 & 657 & 0.785 \\
\hline 15 & Khuzestan & 444 & 0.020519 & 4710509 & 94.25732973 & 64055 & 10 & 73.5 & 662 & 0.802 \\
\hline 16 & Yazd & 725 & 0.033506 & 1138533 & 636.7843532 & 73477 & 1230 & 15.5 & 486 & 0.824 \\
\hline 17 & Zanjan & 394 & 0.018209 & 1057461 & 372.5905731 & 19164 & 1638 & 55.2 & 371 & 0.771 \\
\hline 18 & Kurdistan & 238 & 0.010999 & 1603011 & 148.4705969 & 29137 & 1463 & 55.0 & 449 & 0.743 \\
\hline 19 & Ardabil & 289 & 0.013356 & 1270420 & 227.4838242 & 17800 & 1338 & 71.4 & 625 & 0.756 \\
\hline 20 & Kermanshah & 175 & 0.008088 & 1951443 & 89.67722859 & 24998 & 1374 & 78.1 & 423 & 0.796 \\
\hline 21 & Kerman & 169 & 0.00781 & 2938988 & 57.50278667 & 183285 & 1760 & 16.0 & 864 & 0.778 \\
\hline 22 & Hamadan & 243 & 0.01123 & 1758264 & 138.2045017 & 20173 & 1803 & 87.2 & 280 & 0.775 \\
\hline 23 & $\begin{array}{l}\text { Sistan and } \\
\text { Baluchestan }\end{array}$ & 134 & 0.006193 & 2775049 & 48.28743565 & 180726 & 1344 & 15.4 & 1340 & 0.688 \\
\hline 24 & Hormozgan & 148 & 0.00684 & 1776415 & 83.31386528 & 70697 & 9 & 25.1 & 1143 & 0.768 \\
\hline 25 & $\begin{array}{l}\text { South } \\
\text { Khorasan }\end{array}$ & 178 & 0.008226 & 768898 & 231.500147 & 151193 & 1444 & 5.1 & 1021 & 0.757 \\
\hline 26 & $\begin{array}{l}\text { North } \\
\text { Khorasan }\end{array}$ & 168 & 0.007764 & 863092 & 194.6490061 & 28434 & 1086 & 30.4 & 831 & 0.745 \\
\hline 27 & $\begin{array}{l}\text { Chaharmahal } \\
\text { and Bakhtiari }\end{array}$ & 68 & 0.003143 & 947763 & 71.74789478 & 16328 & 2066 & 58.0 & 383 & 0.798 \\
\hline 28 & Ilam & 183 & 0.008457 & 580158 & 315.4313135 & 20103 & 1427 & 28.9 & 594 & 0.815 \\
\hline 29 & $\begin{array}{l}\text { West } \\
\text { Azarbaijan }\end{array}$ & 395 & 0.018255 & 3265219 & 120.9719777 & 37411 & 1363 & 87.3 & 800 & 0.758 \\
\hline 30 & $\begin{array}{l}\text { Kohgiluyeh } \\
\text { and Boyer- } \\
\text { Ahmad }\end{array}$ & 73 & 0.003374 & 713052 & 102.3768253 & 15504 & 1864 & 46.0 & 611 & 0.791 \\
\hline 31 & Bushehr & 55 & 0.002542 & 1631403 & 33.71331302 & 23198 & 4 & 70.3 & 896 & 0.812 \\
\hline
\end{tabular}

*Cumulative Frequency

$* * \mathrm{ACF}=\mathrm{CF} /$ Population $* 1000000$

***Human Development Index 
Table 2. Clustering provinces based on the cumulative frequency and adjusted cumulative frequency of the infected cases.

\begin{tabular}{|c|c|c|c|c|c|}
\hline Province & $\mathrm{CF}$ & Cluster Membership & Province & $\mathrm{ACF}$ & Cluster Membership \\
\hline Tehran & 5098 & 1 & Tehran & 384.4645551 & 1 \\
\hline Isfahan & 1976 & 2 & Isfahan & 385.873439 & \\
\hline Mazandaran & 1700 & 3 & Zanjan & 372.5905731 & \\
\hline Gilan & 1191 & \multirow[t]{3}{*}{4} & Qom & 911.5650365 & \multirow[t]{2}{*}{2} \\
\hline Qom & 1178 & & Semnan & 918.3324791 & \\
\hline Alborz & 1177 & & Gilan & 470.6215207 & \multirow[t]{2}{*}{3} \\
\hline Markazi & 882 & \multirow[t]{3}{*}{5} & Alborz & 433.9330482 & \\
\hline Razavi Khorasan & 858 & & Mazandaran & 517.7337515 & \multirow[t]{2}{*}{4} \\
\hline East Azarbaijan & 813 & & Qazvin & 525.216269 & \\
\hline Yazd & 725 & \multirow[t]{3}{*}{6} & Markazi & 617.0097413 & \multirow[t]{2}{*}{5} \\
\hline Qazvin & 669 & & Yazd & 636.7843532 & \\
\hline Semnan & 645 & & East Azerbaijan & 207.9468966 & \multirow[t]{5}{*}{6} \\
\hline Golestan & 391 & \multirow[t]{6}{*}{7} & Golestan & 209.2454374 & \\
\hline Fars & 505 & & Ardabil & 227.4838242 & \\
\hline Lorestan & 476 & & South Khorasan & 231.500147 & \\
\hline Khuzestan & 444 & & North Khorasan & 194.6490061 & \\
\hline Zanjan & 394 & & Razavi Khorasan & 133.3436734 & \multirow[t]{9}{*}{7} \\
\hline West Azarbaijan & 395 & & Kurdistan & 148.4705969 & \\
\hline Kurdistan & 238 & \multirow[t]{3}{*}{8} & Fars & 104.0963673 & \\
\hline Ardabil & 289 & & Kermanshah & 89.67722859 & \\
\hline Hamadan & 243 & & Khuzestan & 94.25732973 & \\
\hline Kermanshah & 175 & \multirow[t]{7}{*}{9} & Hamadan & 138.2045017 & \\
\hline Kerman & 169 & & West Azarbaijan & 120.9719777 & \\
\hline Sistan and Baluchestan & 134 & & Kohgiluyeh and Boyer-Ahmad & 102.3768253 & \\
\hline Hormozgan & 148 & & Hormozgan & 83.31386528 & \\
\hline South Khorasan & 178 & & Lorestan & 270.3548521 & 8 \\
\hline North Khorasan & 168 & & Kerman & 57.50278667 & \multirow[t]{4}{*}{9} \\
\hline Ilam & 183 & & Sistan and Baluchestan & 48.28743565 & \\
\hline Chaharmahal and Bakhtiari & 68 & \multirow[t]{3}{*}{10} & Chaharmahal and Bakhtiari & 71.74789478 & \\
\hline Kohgiluyeh and Boyer-Ahmad & 73 & & Bushehr & 33.71331302 & \\
\hline Bushehr & 55 & & Ilam & 315.4313135 & 10 \\
\hline
\end{tabular}

*Dark red- Red- Orange- Yellow- White show very high, high, moderate, low, very low level of COVID-19 outbreak.

Figures 


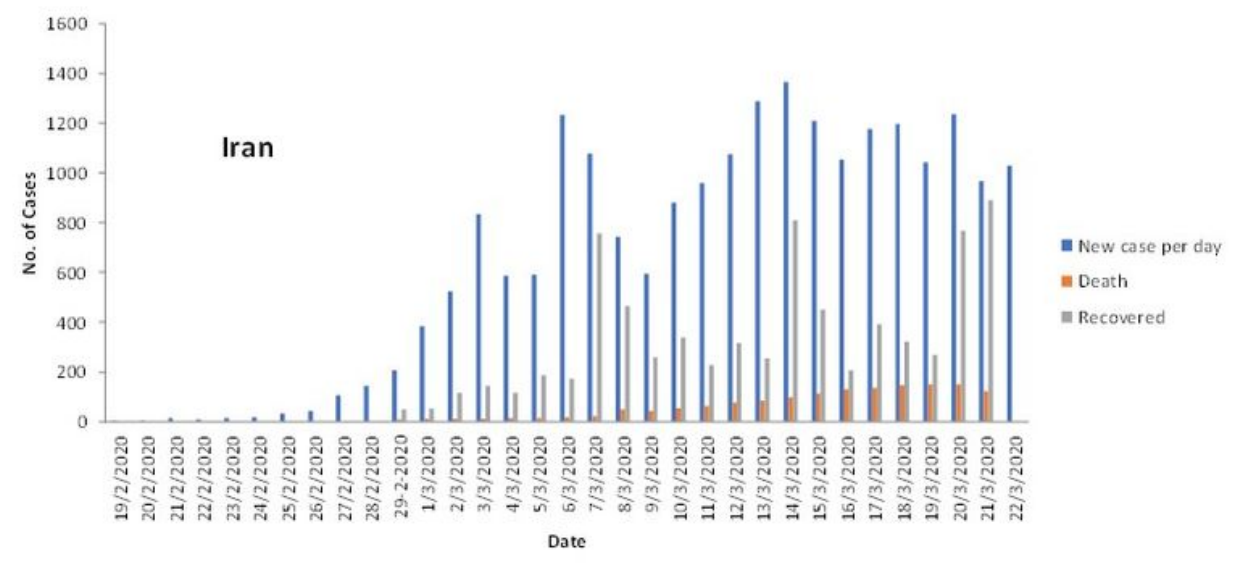

Figure 1

Number of new cases, Death and recovered from COVID-19, Feb 19 to Mar 22, 2020. 


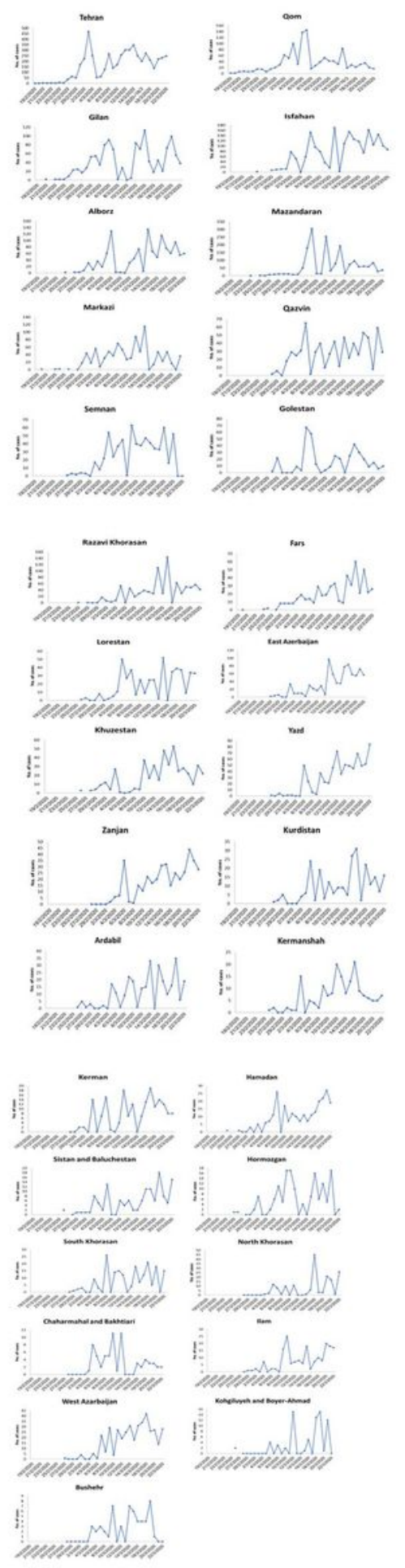

Figure 2

Number of new confirmed cases of COVID -19 in provinces, Feb 19 to Mar 22, 2020. 


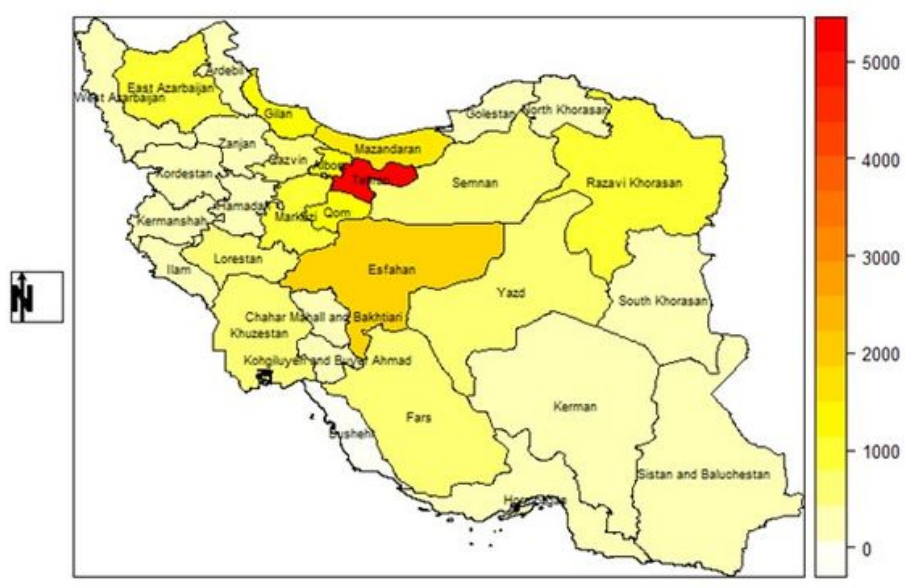

\section{Figure 3}

Cumulative frequency of new confirmed cases of COVID -19, Feb 19 to Mar 22, 2020. RStudio software version 1.2.5042 (https://rstudio.com/products/rstudio/download/) is used to create this map.

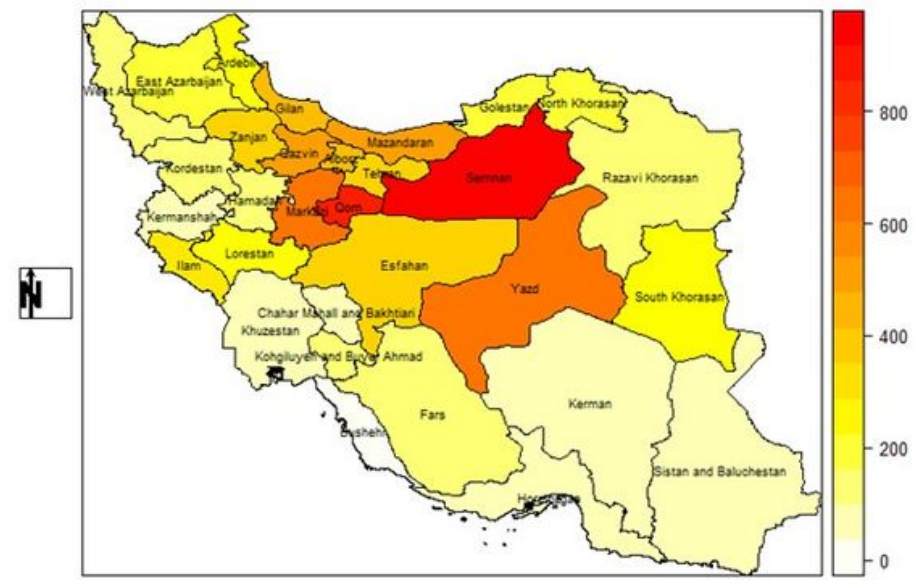


Figure 4

Adjusted cumulative frequency of new confirmed cases of COVID -19, Feb 19 to Mar 22, 2020. RStudio software version 1.2.5042 (https://rstudio.com/products/rstudio/download/) is used to create this map.

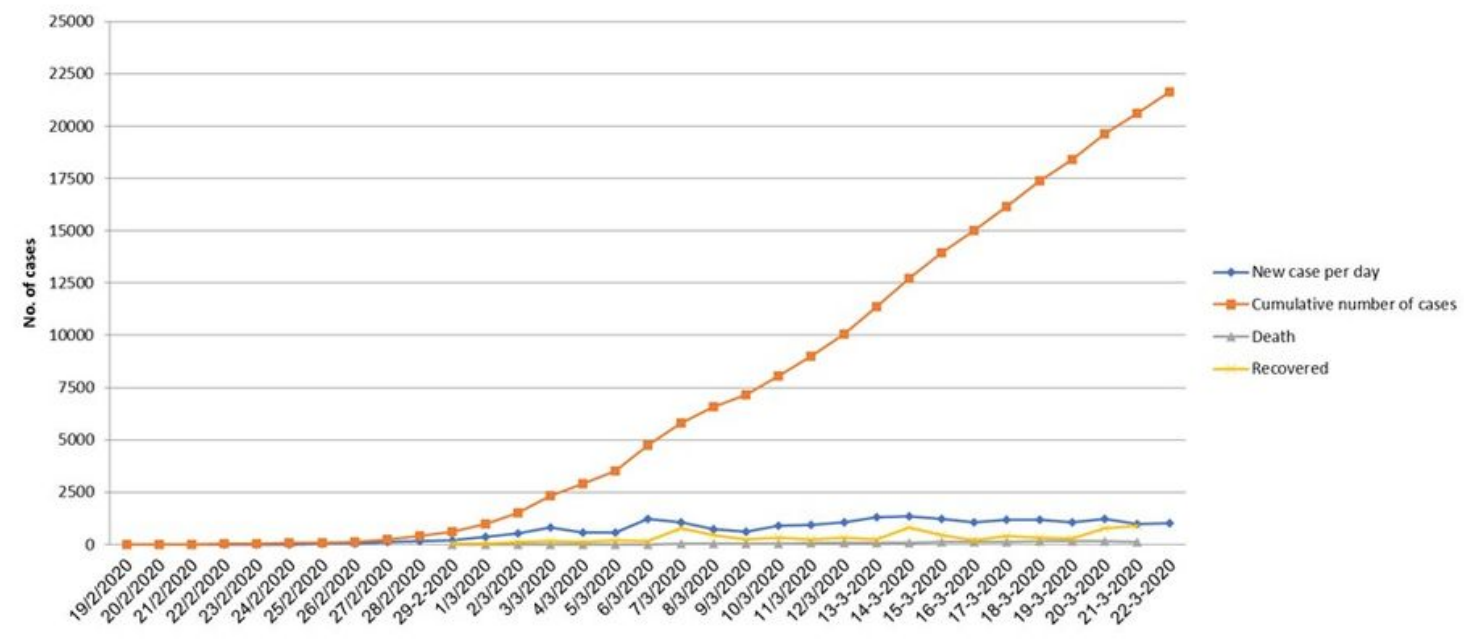

Figure 5

Number of new cases, cumulative, death and recovered from COVID 19 per day in Iran. 


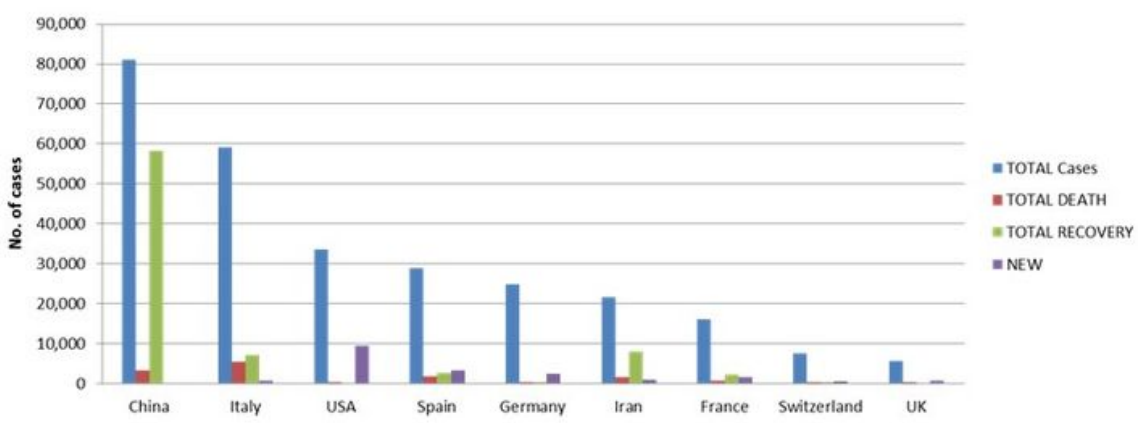

Figure 6

Comparing Iran with other countries according to COVID-19 during the study period. 